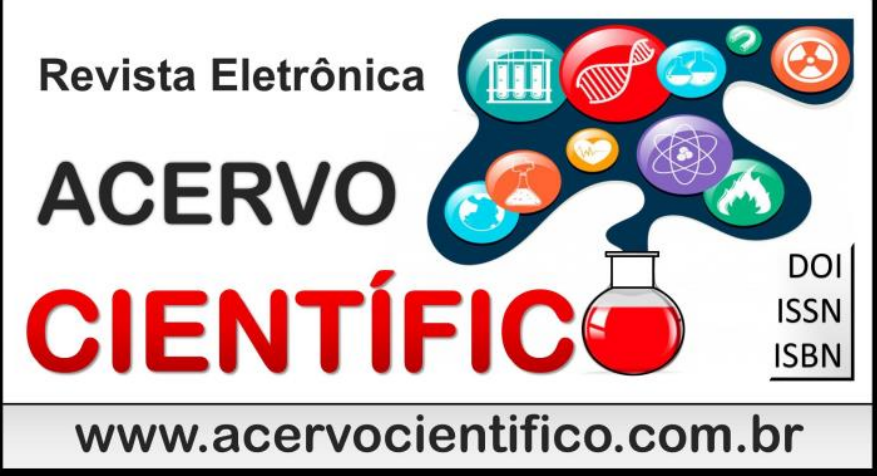

\section{ARTIGO DE REVISÃO}

\author{
Recebido em: 8/2018
}

Aceito em: 8/2018

Publicado em: 9/2018

DOI: 10.25248/REAC.e330.2019

\title{
Interação como defesa da marca nas redes sociais: estudo de caso de uma empresa aérea
}

\author{
Ranieldo Barreiras Barbosa Souzaํㅗㄹ Antônio José da Silva Filho².
}

\begin{abstract}
Resumo: O artigo pretende mostrar a importância de uma estratégia de defesa da marca em busca da reputação da imagem corporativa mediante ataques e críticas aos produtos, serviços e marcas nas redes sociais. Para tanto será realizada a análise da fan page de uma empresa aérea em uma rede social conhecida mundialmente. Foram analisados três períodos que compreende os meses de Novembro e Dezembro dos anos 2010 e 2012. O estudo avalia os componentes de comunicação e marketing junto aos públicos estratégicos da organização com objetivo de defender a imagem diante de comentários e críticas que possam expor negativamente os produtos e serviços da marca.
\end{abstract}

Palavras-chave: Marca; Tecnologia; Redes Sociais; Reputação; Reputação; Empresa Aérea.

\begin{abstract}
The article intends to show the importance of a brand defense strategy in search of corporate image reputation through attacks and critiques of products, services and brands in social networks. For that, the analysis of the fan page airline company will be carried out. Three periods were analyzed, covering the months of November and December of the years 2010 and 2012. The study evaluates the communication and marketing components with the strategic public of the organization in order to defend the image in the face of comments and criticisms that may expose products and services.
\end{abstract}

Keywords: Brand; Tecnology; Social Networks; Reputation; Airline Company.

Resumen: El artículo pretende mostrar la importancia de una estrategia de defensa de la marca en busca de la reputación de la imagen corporativa mediante ataques y críticas a los productos, servicios y marcas en las redes sociales. Para ello se realizará el análisis de la fan page de una empresa aérea. Se analizaron tres períodos que abarca los meses de noviembre y diciembre de los años 2010 y 2012 . El estudio evalúa los componentes de comunicación y marketing junto a los públicos estratégicos de la organización con el objetivo de defender la imagen ante comentarios y críticas que puedan exponer negativamente los productos y servicios de la marca.

Palabras clave: Marca; Tecnologia; Rede Social; Reputación; Empresa Aérea.

\footnotetext{
1 Universidade Federal do Oeste da Bahia (UFOB). *E-mail: ranieldosouza89@gmail.com

2 Universidade Dom Pedro II (UNIDOM).
} 
Revista Eletrônica Acervo Científico / Electronic Journal Science Collection ISSN 2595-7899

\section{INTRODUÇÃO}

Por meio do estudo da Fan Page de uma empresa aérea na rede social, em três períodos de análise que compreendem novembro e dezembro de 2010, 2011 e 2012, o presente estudo vem não apenas para corroborar os estudos e opinião consolidada da importância das empresas nas redes sociais, busca também entender e demonstrar as estratégias, dificuldades e os percalços na gestão do relacionamento nas redes sociais, neste caso em especifico da empresa aérea estudada.

Por meio do monitoramento da atuação e desta gestão nas redes sociais, o estudo vai trazer alguns indícios de como uma gestão transparente e criativa nas redes sociais podem impactar nas imagens institucionais da marca, produto ou serviço. O artigo aborda teorias sobre Marketing Digital ${ }^{3}$ e Branding ${ }^{4} \mathrm{em}$ redes sociais, sendo dividido em quatro partes: 1) A primeira retrata o desenvolvimento da Internet e das Redes Sociais; 2) A segunda sobre a importância de instituições, principalmente as empresas, estarem conectadas às redes sociais; 3 ) a terceira sobre a gestão das marcas das empresas nas redes sociais; e 4) a última parte evidencia a interação da empresa aérea em sua Fan Page para a defesa da marca corporativa.

\section{Internet e redes sociais}

A Internet e a rede social reformularam o modo de pensar, agir e se posicionar das pessoas na sociedade. As redes sociais remontam desde o momento em que os indivíduos começaram a conviver em grupo e vem da necessidade humana de compartilhar e criar vínculos entre si.

Desde o surgimento da Internet, no início da década de 90, foram realizadas tentativas e esforços para desenvolvimento de uma interação virtual que possibilitasse romper o tempo e espaço, com o início pela troca de mensagens por e-mails, seguido pelos "chats" e softwares de troca de mensagens instantâneas como MIRC, AOL Instant Messanger e ICQ e chegando depois com a criação de redes sociais como Classmates, em 1995, Sixdegress, em 1997, Friedster em 2002, My Space e Linkedin em 2003.

O grande boom das redes sociais na Internet aconteceu a partir de 2004, com a WEB.2.0 $0^{5}$ a criação e disseminação do Orkut em 2004, e do Facebook, a partir de 2005. Considerada a segunda geração de serviços online, a WEB 2.0 é considerada aquele estágio em que se potencializou as formas de publicação, compartilhamento e organização de informações, além de ampliar os espaços para a interação entre os participantes do processo (PRIMO, 2007).

É nesta fase onde se encaixam as redes sociais e tem início o aperfeiçoamento das plataformas e o design prático e amigável, aumentando cada vez mais a complexidade no intercâmbio de informações interferindo nos fluxos das mídias tradicionais. Segundo Recuero (2009), o surgimento das redes sociais complexificou ainda mais os fluxos informacionais.

[...] "A grande diferença entre sites de redes sociais e outras formas de comunicação mediada pelo computador é o modo como os primeiros permitem a visibilidade e a articulação com as redes sociais, a manutenção dos laços sociais estabelecidos no espaço off-line". (pág.21)

Ao contrário da publicidade nas mídias tradicionais, o boom das redes sociais aliado aos baixos custos e a interação direta com os públicos estratégicos atraíram as empresas para gerirem as suas marcas também nas redes sociais. Para Costa e Covalesqui (2012), as redes sociais se transformaram em um poderoso

\footnotetext{
${ }^{3}$ [...] "Marketing Digital consiste em usar tecnologias da informação baseadas na Internet e todos os dispositivos que permita seu acesso para realizar comunicação com intenção comercial entre uma empresa e seus clientes ou potenciais clientes". (Souza, 2012, pág. 34)

${ }^{4}[. .$.$] "Branding preocupa-se com uma marca desde a sua simbolização gráfica passando por estratégias integradas e$ multidisciplinares com o objetivo de aumentar o valor percebido e indo até a geração de influência favorável e presente na cultura do público-alvo". (Coelho, 2012, pág. 9)

${ }^{5}$ [...]“WEB 2.0 é um termo criado em 2004 por Tim O’Reilly para designar uma segunda geração de comunidades e serviços tendo como conceito a "Web como plataforma" envolvendo wikis, aplicativos baseados em folksonomia, redes sociais e tecnologia da informação. (Souza, 2012, pág. 18)
} 
meio de comunicação capaz de agregar pessoas e fazê-las gerir e disseminar o conteúdo à medida que possibilita comunicação de todos, aumentando exponencialmente o alcance das mensagens.

\section{Gestão da marca nas redes sociais}

Ao entrarem na Internet, em busca de um diferencial competitivo e relacionamento direto com os públicos estratégicos, as instituições compreenderam que não podem mais utilizar de amadorismo, devendo valer-se do profissionalismo para gerar conteúdo afinado com as expectativas do público alvo.

Novas soluções precisaram ser criadas e estabelecidas para gerir o processo de comunicação dentro das instituições, introduzindo um novo composto organizacional baseado nas áreas de tecnologia de informação para a formação de uma rede descentralizada e de comunicação minimizando os impactos desta nova realidade que se tornaram essenciais neste processo.

Para instituições alinhadas ao comércio eletrônico e que mantém a Internet como a chave para o negócio, o branding, também chamado de gestão das marcas, torna-se essencial. Para Coelho (2009), empresas de diferentes segmentos e tamanhos intensificam o olhar sobre o ambiente digital na busca com a conexão direta com cada consumidor e na tentativa de buscar mais uma forma de diferenciação corporativa.

[...] "Dessa forma, salienta-se que cada empresa é efetivamente responsável por suas ações e supressões no que se refere a construção de uma imagem corporativa sólida. Atuar ou negligenciar o uso das novas tecnologias é, sem dúvida, uma decisão de cada organização".(Coelho, 2009, pág. 7)

Juntamente com a exposição, as empresas precisam estar estrategicamente preparadas para responder e se defender de maneira transparente aos comentários e opiniões publicadas na rede que possam arranhar sua marca.

[...] "Acredita-se que a utilização adequada das novas técnicas digitais possa auxiliar na ampliação do alcance da atuação corporativa, bem como reforçar os laços afetivos do público com a organização, e ainda, colaborar com o crescimento e visibilidade da marca" (Coelho, 2009, p.7)

\section{ESTUDO DE CASO}

\section{Marketing digital da empresa aérea estudada}

A empresa TAM, objeto de pesquisa deste estudo, se juntou ao Facebook no dia 14 de dezembro de 2009 quando passou a se relacionar com os seus públicos por meio da sua Fan Page.

Segundo Gollner e Goulart (2002) a opção das empresas pelo Facebook se dá pela sua utilização em massa a nível mundial com trocas de informações e produção cultural representando hoje não apenas mais um fenômeno tecnológico, mas também um fenômeno social, cultural e comunicacional. De acordo com a pesquisa Avenade 6 o Facebook tem $74 \%$ de participação entre os entrevistados. No Brasil, ele teve uma média ainda maior que a global, ocupando $75 \%$ da participação, seguido do Twitter (49\%) e Linkedin (47\%).

Em um movimento bastante promissor, as instituições veem nas redes sociais uma forma de aperfeiçoar - seu relacionamento com os seus públicos estratégicos, e de forma planejada, obter vantagens principalmente comerciais. Nesta linha entram as grandes empresas de varejo em seus sites na Internet que começaram a criar em seus perfis promoções, responder reclamações e mobilizar os seus públicos alvos para que possam efetivar compras. As companhias aéreas, como a empresa aérea avaliada no presente estudo, se encaixa neste perfil.

\section{Fan Page da empresa aérea para relacionamento na rede social}

\footnotetext{
${ }^{6}$ Disponível em http://computerworld.uol.com.br/tecnologia/2013/06/07/rede-social-e-usada-por-97-das-empresas-nomercado-global/ Acesso no dia 14 de agosto de 2013. às 14h
} 
Grande parte do crescimento do Facebook acontece, sem dúvida, por conta do relacionamento entre os consumidores e as marcas, proporcionado através das Fan Pages. Segundo o Facebook, essas páginas existem para que as organizações, empresas, celebridades transmitam muitas informações aos seus seguidores.

Em sua própria página o Facebook ${ }^{7}$ informa que qualquer usuário pode criar uma página de uma marca, entidade (local ou organização) ou figura pública, sendo o conteúdo público e visível a qualquer pessoa que queira ver a página. Sobre o gerenciamento de páginas, o Facebook recomenda que os nomes das páginas e os endereços da WEB devem refletir com precisão o conteúdo da página. Na Fan Page é permitido anúncios e conteúdo comercial. Todas as capas são publicas o que significa que qualquer pessoa que visitar a página poderá vê-las.

Em sua Fan Page ${ }^{8}$ o Facebook informa que foi aberta para acesso aos universitários no dia 4 de fevereiro de 2004 e para estudantes de nível médio em 3 de setembro de 2005. Em 26 de setembro de 2005 ele se abre para toda a sociedade. A primeira postagem foi em sua própria Fan Page e ocorreu no dia 25 de março de 2008 , ficando a ferramenta disponível para todas as instituições.

\section{Regras para Defesa da Reputação e da Credibilidade da empresa aérea e da rede social}

Uma pesquisa realizada pela $\mathrm{H}$. Mídia e $\mathrm{M}$. Sense ${ }^{9}$, que analisou 484 pessoas em todo o Brasil durante março de 2012, perguntou se as redes sociais facilitam o relacionamento com as empresas. Do total $65 \%$ dos pesquisados concordam que facilita, ou seja, a interatividade entre clientes e marcas nas redes sociais não pode ser negligenciada e nem estar fora de um planejamento estruturado e uma execução alinhada ao planejamento estratégico e ao marketing da instituição.

É o caso da TAM Airlines, cuja Fan Page no Facebook ${ }^{10}$ possui cerca de 1,153,542 curtidas. A TAM entrou no facebook no dia 14 de dezembro de 2009, mas passou a ter sua Fan Page apenas no dia 11 de novembro de 2010. Este trabalho, no entanto, avaliará apenas a Fan Page, por ser a ferramenta utilizada atualmente pela TAM no Facebook e com o conteúdo atualmente disponível.

\section{Estratégia de Defesa da Reputação e da Credibilidade da empresa na internet}

Para avaliar como a equipe de marketing da empresa aqui estudada se preocupou com a credibilidade e reputação da marca na Internet, o presente estudo avaliou a Fan Page nos meses de novembro e dezembro dos anos de 2010, 2011 e 2012. Os meses de novembro e dezembro foram escolhidos por darem início à produção de conteúdo. E a avaliação no mesmo período nos dois próximos anos para compreender como a empresa mudou a estratégia de defesa da sua reputação e credibilidade da sua marca diante dos ataques dos seguidores na rede social

A pesquisa foi realizada entre os dias 15 de junho e 15 de agosto em que foram analisados 95 postagens e seus comentários dos meses de novembro e dezembro dos anos de 2010, 2011 e 2012. A pesquisa contabilizou em seus quadros a quantidade de postagens "curtidas", compartilhamentos e comentários. Como o objetivo é entender como o administrador da Fan Page da empresa aérea se defende de ataques e responde às reclamações, também foram avaliados os comentários e foi realizada uma estimativa com a quantidade de reclamações, de postagens do administrador e quais respondiam diretamente as reclamações dos internautas.

Embora haja uma tentativa de quantificação, o alto volume de comentários a serem analisados, bem como a exclusão desses comentários pelo administrador da Fan Page seguindo os "Termos e Condições de

\footnotetext{
${ }^{7}$ Disponível em https://www.facebook.com/page guidelines.php. Acesso no dia 27/07/2013, äs 17 h07.

${ }^{8}$ Disponível em https://www.facebook.com/facebook?fref=ts. Acessado no dia 27/07/2013, äs 17h43.

${ }^{9}$ Disponível em http://www.hi-midia.com/pesquisas/abril2012-redes-sociais-comportamento-dos-usuarios/. Acesso em

14 de agosto de 2013, às $15 \mathrm{~h} 45$.

10 Disponível em https://www.facebook.com/TAMAirlines?hc location=stream Acesso no dia 25/07/2013, às 15h10
} 
Uso" e avaliação subjetiva da pesquisa, a contagem das reclamações serve apenas como uma referência, sendo apenas uma estimativa que leva a entender como a Fan Page se defende das reclamações dos fans.

\section{Avaliação da Fan Page - Novembro e Dezembro de 2010}

Em sua primeira postagem, em 11 de novembro de 2010, a aérea postou três fotos do espaço interno da sua aeronave com o título "Paixão por Voar e Servir", essa postagem teve 22 curtidas, 2 compartilhamentos e 4 comentários, sendo um deles de teor negativo e que não obteve resposta.

Em novembro de 2010, no início das postagens da Fan Page da empresa, destaca-se a ausência de interação do perfil com os seguidores da Fan Page, a exceção de uma errata. Das 16 postagens, 15 foram institucionais, sendo que 8 foram reproduções de links de seu blog, 7 imagens de aeronaves e projetos e 1 reprodução de link de reportagem da rede Globo.

A maioria das postagens nos primeiros meses da Fan Page restrigem a descrever o conteúdo do blog, o que dificulta a interação. Ao contrário, percebe-se uma maior interação com maior quantidade de curtidas, comentários e compartilhamentos dos seguidores diante de imagens, ao contrário da reprodução de conteúdos escritos com links do blog da empresa.

O principal agravante neste período foi a total ausência de interação pelos administradores às críticas e reclamações. Por causa da transparência das redes sociais, como forma de solucionar o seu problema as pessoas também recorreram ao Facebook para tornar pública a sua insatisfação, e não houve nenhum tipo de interação do administrador da Fan Page. Nesses casos, ao invés de divulgação na rede social por causa dos comentários, a publicidade pode se tornar essencialmente negativa, prejudicando a imagem da instituição.

\section{Avaliação da Fan Page - Novembro e Dezembro de 2011}

Nos meses de novembro e dezembro de 2011 foram postadas pela empresa aérea em sua Fan Page, 34 tópicos, superando o dobro de postagens do mesmo período de 2010. A principal diferença foi a mudança na política das postagens, com conteúdos voltados ao comercial diretamente ligado para o incremento das vendas. Do total, 19 foram de caráter comercial ou promocional e 5 institucionais.

Neste período, percebe-se que os usuários insatisfeitos utilizam o espaço de comentário das postagens para reclamar da empresa depois que passaram por outros canais de atendimento disponíveis como atendimento por telefone, e-mail ou conversação instantânea e não tiveram seus problemas resolvidos. No total das postagens 127 foram reclamações ou críticas diretas aos serviços e atendimento da companhia aérea distribuídas em 14 postagens. Apesar da menor quantidade de postagem, em relação ao mesmo período de 2010, houve cinco vezes mais reclamação. Por causa do aumento da quantidade de seguidores da Fan Page, e talvez, por entenderem este como um canal legítimo para reclamação.

Para Moreira e Patriota (2010) os impactos na relação marca-cliente intensificou o aumento da chamada informação boca a boca. Cada vez mais os clientes insatisfeitos se esquecem dos Serviços de Atendimento ao Consumidor (SAC's) e reclamam diretamente nas redes sociais.

Ainda segundo os autores, uma das principais motivos para que as empresas se preocupem com reclamações e opiniões negativas sobre a marca nas redes sociais é a credibilidade dos comentários e reclamações, consideradas altamente confiáveis pelos seus pares, no caso dos consumidores dos produtos e serviços de uma determinada marca.

Ao perceber estas mudanças, percebe-se que o administrador da Fan Page da TAM Linhas Aéreas passou a interagir com os usuários principalmente os críticos e que reclamam dos seus serviços. Nesse caso, foram levantadas 65 respostas especificas aos seguidores. Embora seja uma estimativa, a pesquisa aponta que o administrador redimensiona os usuários para os canais de reclamação chamados oficiais. 
Neste caso um espaço virtual para o atendimento ao consumidor e para outra rede social, twitter, que tem um sistema de registro menos público do que o Facebook. Independente se o propósito é alertar outros consumidores, demonstrar a sua insatisfação ou atacar a marca, Moreira e Patriota (2010) acreditam que as empresas precisam se preparar para defender a sua reputação nas redes sociais. $O$ marketing das empresas deve montar estratégias adequadas, com equipe e orçamento específico, para gerir a marca nas redes sociais.

As crises nas redes sociais podem se tornar uma oportunidade de melhoria e crescimento, além de se transformar em diferencial competitivo para a gestão de novos processos para aperfeiçoar produtos, serviços e marcas. "As empresas preocupadas com a imagem da marca e acompanhando o monitoramento da mensagem divulgada pelos consumidores, sentem-se convidadas a responder principalmente para sair em defesa da marca" (COSTA e COVALESQUI, 2012, p.1).

\section{Avaliação da Fan Page - Novembro e Dezembro de 2012}

A empresa aqui estudada internalizou a diretriz voltada para a maior interatividade, o que pode se comprovar nos dados mais atuais do levantamento, de novembro e dezembro de 2012 quando existe uma interação com os usuários nos comentários. O levantamento aponta 45 postagens no período, ultrapassando as 36 no mesmo período de 2001, sendo 28 com o conteúdo comercial ou promocional, e 17 institucionais.

Ao levar em consideração as postagens com a maior quantidade de comentários, houve um aumento considerável nas interações dos fans ao longo dos três períodos levantados pela pesquisa. Em 2010, foram 32 comentários; em 2011, 09; e em 2012, 2851. Além da exclusão dos comentários pelo administrador, a grande quantidade de material a ser analisado também prejudicou a quantificação da quantidade de comentários, e de interações no perfil. A pesquisa reforça que os dados servem como parâmetro de avaliação.

Juntamente com a quantidade de comentários, também aumentou a quantidade de reclamações. A pesquisa estima 345 reclamações, sendo que 253 foram diretamente respondidas. A maioria das postagens ainda se limita a reforçar a política de institucionalizar os canais oficiais, pedido de informações para que possam cadastrar oficialmente a reclamação. Em relação ao mesmo período de 2012, o administrador começou a postar respostas mais flexíveis saindo do padrão, ao postar comentários de resposta aos questionamentos e agradecimentos.

Para Costa e Covalesqui (2010), apesar dos riscos da alta exposição e da proximidade com o público, as empresas permanecem nas redes sociais pela influencia que podem exercer, e até mesmo como forma de receber de forma monitorada e gratuita um retorno dos clientes e públicos estratégicos.

Outra proposta é agregar outras mídias, mas sem perder a especificidade do público na rede social. Existem postagens da Fan Page da mesma empresa de fotos dos clientes em outra rede social, Instagram (rede social focada na postagem de imagens) e de informações do TAM nas Nuvens. Nestes casos, a mensagem vem com um texto rápido de no máximo cinco linhas finalizado por um link para dimensionar quem mais se interessar a ver a foto ou o vídeo. $E$ todas as postagens também estão atreladas a uma imagem.

Toda a estratégia possibilita ao seguidor uma maior conexão e interação com a marca fortalecendo e aumentando os níveis de reputação e credibilidade das informações comerciais e institucionais. $E$ atender as reclamações e os questionamentos dos públicos estratégicos, e principalmente, dos clientes insatisfeitos com os serviços da companhia, é condição básica para que a transparência também nas redes sociais possa reverter em confiança e fidelidade dos clientes à marca, o que influencia diretamente na venda dos seus serviços.

\section{CONSIDERAÇÕES FINAIS}


Ao avaliar a Fan Page da TAM Linhas Aéreas, percebe-se que o imediatismo e instantaneidade proporcionados pela Internet e pelas redes sociais mudaram as exigências dos clientes. $O$ imediatismo da Internet, principalmente daqueles clientes que consomem os produtos e serviços diretamente da rede também referenda o direito dos clientes reclamarem pelos mesmos meios que consomem os produtos. Dispositivos cada vez mais portáteis como tablets e smartphones com interfaces específicas para as redes sociais possibilita a reclamação em tempo real dos clientes insatisfeitos.

No caso específico dessa empresa aérea, sua Fan Page conseguiu estabelecer uma interação com os clientes e estabelece o diálogo diante de conflitos e reclamações. Por parte dos clientes, percebe-se que a Fan Page vem sendo utilizada quando todos os canais oficiais se esgotam, e insatisfeitos precisam dar vazão na Fan Page.

O fato da Fan Page ser considerada pelo cliente um espaço público e aberto de reclamação e um local para dissipar o conflito, a companhia pode aproveitar a oportunidade para identificar falhas e propor melhorias. Cassal e Oliari (2012) acreditam que quando uma empresa está inserida nas mídias sociais, ela aprende diretamente com seus usuários, pois através de avaliações gratuitas e muito mais valiosas do que a publicidade tradicional, pode-se entender detalhadamente as opiniões dos usuários finais de seus produtos ou serviços de uma forma simples, verdadeira e espontânea.

Outra vantagem é deixar o espaço de reclamações restrito evitando que públicos que não tenham nenhum tipo de interação com a marca seja impactado negativamente. Ao ter a Fan Page, a empresa tem a oportunidade de falar diretamente com o seu cliente, além de monitorar pequenos incidentes e tentar resolvê-los antes que se transformem em crises.

Ao lutar pela transparência nas informações ou de tentar resolver os conflitos com os clientes insatisfeitos publicamente em sua Fan Page, a empresa avaliada por este estudo se posicionou como uma companhia moderna e com uma comunicação eficaz e transparente com os seus públicos estratégicos. $\mathrm{O}$ que reforça a sua credibilidade e reputação e pode influenciar a decisão de consumo e impactando positivamente a opinião pública, sendo levado em consideração em momentos de crise mais sérias as quais as companhias aéreas estão sujeitas.

\section{REFERÊNCIAS}

1. AAKER, DAVID A. MARCAS, brand equity, gerenciando o valor da marca. Trad. André Andrade. São Paulo: Negócio Editora, 1998, $317 p$

2. BARBOSA, DENIS BORGES. Uma introdução à propriedade intelectual. Lúmen Júris. Rio de Janeiro, 2003,1268p.

3. CÉSPEDES,LIVIABRASIL. Constituição da República Federativa do Brasil - 05.10.1988. SARAIVA, 2016, 71p.

4. LEVY, PIERRE. CIBERCULTURA/PIERRE LÉVY; tradução de Carlos Irineu da Costa - São Paulo: Ed. 34, 1999,272p.

5. SOARES. JOSÉ CARLOS TINOCO. Marca vs. nome comercial: conflitos. São Paulo: Editora Jurídica Brasileira, 2000,400p.

6. SOUZA, BRUNO DE. Marketing Digital 2.0 - Como sair na frente da concorrência. Espírito Santo: Ed. Clube dos Autores, 2012. $185 \mathrm{p}$.

7. AIRES, GUILHERME MACHADO. O conceito de marca e sua proteção jurídica. Revista CEPPG - № $25-2 / 2011-$ ISSN 1517 8471 - Páginas 115 à 129AIRES, Guilherme Machado. O conceito de marca e sua proteção jurídica. Revista CEPPG - № 25 2/2011 - ISSN 1517-8471 - Páginas 115 à 129

8. BRANDÃO, Vanessa Cardozo. Comunicação e Marketing na Era Digital: Internet como Mídia e Canal de Vendas. Apresentado durante o XXIV Congresso Brasileiro de Ciências da Comunicação - Campo Grande (MS). 2001. 39: 48-52

9. CASSAL, Denise; OLIARI, Deivi Eduardo. A construção da marca por meio da integração das mídias sociais com seus consumidores: Um estudo de caso da Tele-Entrega do Chef Waldemar Express. Trabalho apresentado no GP Publicidade - Marcas e Estratégias do XII Encontro dos Grupos de Pesquisa em Comunicação, evento componente do XXXV Congresso Brasileiro de Ciências da Comunicação. 2012. 76: 81-95

10. COELHO, Débora Ferreira. Digital Branding: uma abordagem sobre a potencialidade das redes sociais na interação e construção da afetividade dos usuários com as marcas no ambiente digital. Trabalho apresentado no GP Publicidade - Marcas e Estratégias do XII Encontro dos Grupos de Pesquisa em Comunicação, evento componente do XXXV Congresso Brasileiro de Ciências da Comunicação. 2012. 94: 170-182

11. DELOITTE. Mídias Sociais nas Empresas - O relacionamento online com o mercado. 2010. 29: 61-75

12. GOLLNER, André Petris e GOULART, Elias Pavão. Curtindo a Mensagem Corporativa: Novos tempos na comunicação organizacional. Trabalho apresentado no GP Relações Públicas e Comunicação Organizacional, XII Encontro dos Grupos de Pesquisas em Comunicação, evento componente do XXXV Congresso Brasileiro de Ciências da Comunicação. 2012. 113: 135-139

13. MOREIRA, Helen; PATRIOTA, Karla Regina Macena P. O uso da Internet para criar interação, relacionamento e experiências com a marca. Artigo apresentado na Divisão Temática Publicidade e Propaganda, da Intercom Júnior - Jornada de Iniciação Científica em Comunicação, evento componente do XXXIII Congresso Brasileiro de Ciências da Comunicação. 2010. 78: 90-96

14. PRIMO, Alex. O aspecto relacional das interações na Web 2.0. E- Compós (Brasília), v. 9, p. 1-21, 2007. 